\title{
Potassium dynamics of a forest soil developed on a weathered schist regolith
}

\begin{abstract}
Soils of the humid tropics are poor in available potassium due to intensive weathering and leaching of nutrients. A study was conducted to investigate the mineralogy and potassium supplying capacity of a forest soil developed on a weathered schist regolith. The quantityintensity $(\mathrm{Q} / \mathrm{I})$ approach was used in thisstudy. The schist regolith showed deep weathering and intense leaching throughout the profile, resulting in low cation exchange capacity (CEC) and available $\mathrm{K}$ in soil and saprolite layers. The mineralogy of the regolith was dominanted by kaolinite, gibbsite and goethite. Feldspar, mica and mica-smectite minerals were observed in the lower saprolite layers. The Q/I parameters showed that the soils and saprolites were low in $\mathrm{K}$ supply power. This observation was attributed to weathering and intense leaching. The free energy values of $K$ replacement $\left(\Delta G r^{\circ}\right)$ also suggest that soils and saprolites of the schist regolith were deficient in $\mathrm{K}$. The $\mathrm{Q} / \mathrm{I}$ parameters significantly correlated with organic carbon and clay content, $\mathrm{CEC}, \mathrm{pH}$ and exchangeable $\mathrm{K}$.
\end{abstract}

Keyword: Potassium; Quality-intensity relationship; Weathered forest soil; Schist; Regolith 